\title{
Gil Courtemanche, Una domenica in piscina a Kigali
}

\section{Veronica Cappellari}

\section{(2) OpenEdition}

\section{Journals}

\section{Edizione digitale}

URL: https://journals.openedition.org/studifrancesi/26948

DOI: 10.4000/studifrancesi.26948

ISSN: 2421-5856

\section{Editore}

Rosenberg \& Sellier

\section{Edizione cartacea}

Data di pubblicazione: 1 avril 2007

Paginazione: 224

ISSN: 0039-2944

\section{Notizia bibliografica digitale}

Veronica Cappellari, «Gil Courtemanche, Una domenica in piscina a Kigali», Studi Francesi [Online], 151

(LI | I) | 2007, online dal 30 novembre 2015, consultato il 23 novembre 2021. URL: http://

journals.openedition.org/studifrancesi/26948 ; DOI: https://doi.org/10.4000/studifrancesi.26948

Questo documento è stato generato automaticamente il 23 novembre 2021.

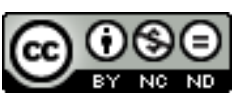

Studi Francesi è distribuita con Licenza Creative Commons Attribuzione - Non commerciale - Non opere derivate 4.0 Internazionale. 


\title{
Gil Courtemanche, Una domenica in piscina a Kigali
}

\author{
Veronica Cappellari
}

\section{NOTIZIA}

GIL COURTEMANCHE, Una domenica in piscina a Kigali, traduzione di Annamaria Ferrero,

Milano, Feltrinelli, coll. "I Narratori”, 2005, pp. 207.

1 Una domenica in piscina a Kigali è la versione in lingua italiana, eseguita da Annamaria Ferrero, del primo romanzo di Gil Courtemanche (titolo originale dell'opera Un dimanche à la piscine à Kigali, Montréal, Les Éditions du Boréal, 2000), un giornalista canadese, a lungo inviato in Africa per Radio Canada, che si è occupato di politica internazionale con particolare attenzione al Terzo Mondo. Il protagonista delle vicende narrate è Bernard Valcourt, reporter e regista quebecchese di mezza età, il quale, dopo aver assistito agli orrori del Vietnam e del Nicaragua, giunge, agli inizi degli anni Novanta, a Kigali, in Ruanda, per compiere un servizio radio-televisivo sull'Aids, malattia che colpisce duramente la popolazione ruandese. Egli visita gli ospedali della città dove si ammassano gli esili corpi, ormai quasi privi di vita, di centinaia di persone sieropositive, per le quali i soccorsi e i medicinali scarseggiano o sono addirittura inesistenti, e ai quali si aggiungono i corpi smembrati e dilaniati dalla cruenta guerra civile in atto tra le due etnie rivali, gli hutu, in ampia maggioranza, e i tutsi, circa il quindici per cento della popolazione ruandese. Affascinato e perfino ammaliato poco per volta da Kigali e dalla sua comunità che, nonostante le brutalità e le paure quotidiane, ama la vita e lotta per la sopravvivenza, Valcourt decide di fermarsi in Ruanda per il resto della propria esistenza, anche perché si è innamorato di Gentille, una giovane e graziosa cameriera di origine hutu ma dai lineamenti e dal portamento tutsi, che, in seguito, prenderà in sposa.

2 L'opera di Gil Courtemanche rende, attraverso lo sguardo estraneo di un quebecchese, triste testimonianza di una nazione «prigionier[a] [di una] storia contorta» (p. 93), 
distrutta da incessanti conflitti e dall'atroce genocidio dei tutsi, dalle tragedie della carestia e della siccità, dall'amara piaga della prostituzione e dell'HIV. Un romanzo denso, a metà tra documentario e finzione, che descrive, con uno stile diretto, senza grandi pretese linguistiche, le atrocità e gli orrori di una nazione dimenticata, forse troppo spesso, dalle istituzioni e dalle organizzazioni internazionali, ma anche un romanzo sull'amore, sui sentimenti, sulle passioni, sulla speranza di trovare, anche in mezzo a tanta disperazione, il desiderio e la forza di vivere una vita che sia vita e non semplice sopravvivenza. 